\title{
Efficient Red Thermally Activated Delayed Fluorescence Emitters Based on a Dibenzonitrile-Substituted Dipyrido[3,2-a:2' ${ }^{\prime} 3^{\prime}$-c]phenazine Acceptor
}

\author{
Lin He, Xuan Zeng, Weimin Ning, Ao Ying, Yunbai Luo * and Shaolong Gong * \\ Department of Chemistry, Hubei Key Laboratory on Organic and Polymeric Optoelectronic Materials, \\ Wuhan University, Wuhan 430072, China; lin_he@whu.edu.cn (L.H.); zengx@whu.edu.cn (X.Z.); \\ wmning@whu.edu.cn (W.N.); yingao96@whu.edu.cn (A.Y.) \\ * Correspondence: ybai@whu.edu.cn (Y.L.); slgong@whu.edu.cn (S.G.)
}

Citation: He, L.; Zeng, X.; Ning, W.; Ying, A.; Luo, Y.; Gong, S. Efficient Red Thermally Activated Delayed Fluorescence Emitters Based on a Dibenzonitrile-Substituted Dipyrido[3,2-a:2', 3'-c]phenazine Acceptor. Molecules 2021, 26, 2427. https: / / doi.org/10.3390/ molecules 26092427

Academic Editors: Mario

Berberan-Santos, Guohua Xie, Chien-Jung Huang and Kuan-Wei Lee

Received: 12 April 2021

Accepted: 17 April 2021

Published: 22 April 2021

Publisher's Note: MDPI stays neutral with regard to jurisdictional claims in published maps and institutional affiliations.

Copyright: (c) 2021 by the authors. Licensee MDPI, Basel, Switzerland. This article is an open access article distributed under the terms and conditions of the Creative Commons Attribution (CC BY) license (https:// creativecommons.org/licenses/by/ $4.0 /)$.
Abstract: How to construct efficient red-emitting thermally activated delayed fluorescence (TADF) materials is a challenging task in the field of organic light-emitting diodes (OLEDs). Herein, an electron acceptor moiety, 3,6-DCNB-DPPZ, with high rigidity and strong acceptor strength was designed by introducing two cyanobenzene groups into the 3,6-positions of a dipyrido[3,2-a:2', $3^{\prime}$-c]phenazine unit. A red-emitting compound, 3,6_R, has been designed and synthesized by combining the rigid acceptor unit with two triphenylamine donors. Due to high molecular rigidity and strong intramolecular charge transfer characteristic in donor-acceptor-donor skeleton, 3,6_R exhibited a red emission with a high photoluminescence quantum yield of $86 \%$ and distinct TADF nature with short delayed fluorescence lifetime of about 1 microsecond. Accordingly, the OLED using 3,6_R as the guest emitter gained a high external quantum efficiency of $12.0 \%$ in the red region with an electroluminescence peak of $619 \mathrm{~nm}$ and favorable Commission Internationale de l'Eclairage coordinates of $(0.62,0.38)$.

Keywords: organic light-emitting diodes; thermally activated delay fluorescence; red emitter; electron acceptor

\section{Introduction}

During the past decade, purely organic emitters exhibiting thermally activated delay fluorescence (TADF) have garnered considerable attention in the field of organic lightemitting diodes (OLEDs) because of their superior ability of harvesting both singlet and triplet excitons for luminance without the use of noble metals [1-5]. By accessing an effective reverse intersystem crossing (RISC) process from the lowest triplet to singlet state with a small singlet-triplet energy gap $\left(\Delta E_{\mathrm{ST}}\right)$, TADF emitters can theoretically achieve up to $100 \%$ internal quantum efficiency in OLEDs [6-8]. Nowadays, efficient organic TADF emitters have been reported in the blue [9-11] and green [12-14] region, facilitated by rational molecular design. Despite this achievement, efficient red-emitting TADF emitters are difficult to construct, especially in the color region having Commission Internationale de l'Eclairage (CIE) coordinates of $(x>0.60, y<0.40)[15-18]$.

Generally, a small $\Delta \mathrm{E}_{\mathrm{ST}}$ to enable an effective RISC process and a strong charge transfer (CT) state to afford a red emission color are two basic design principles for efficient red-emitting TADF emitters [19]. These requirements are inherently detrimental to photoluminescence quantum yield $\left(\Phi_{\mathrm{PL}}\right)$ of red emitters because the spatially isolated frontier molecular orbital distribution required for the small $\Delta E_{\mathrm{ST}}$ normally degrades radiative rate of $S_{1}$ and the narrow energy gaps generally lead to severe non-radiative processes from $S_{1}$ to the ground state [16-18]. Accordingly, red TADF emitters often face the primary limitation of low $\Phi_{\mathrm{PL}}$ [19-21]. To address this issue, electron donor (D) and/or acceptor (A) moieties with high rigidity are usually adopted in the pre-twisted D-A or D-A-D motif for designing red TADF emitters [22-26]. So far, a few electron acceptors with 
strong acceptor strength and large conjugation have been reported to construct red TADF emitters, for example, heptazine [27], dibenzo[f,h]quinoxaline-2,3-dicarbonitrile [26,28], and dibenzo[a,c]phenazine-3,6-dicarbonitrile [29,30]. Despite these progresses, most of red TADF emitters have moderate $\Phi_{\mathrm{PL}}$ values of below $70 \%[19,31]$. Thus, further efforts are still required to design new electron acceptors with high rigidity and strong acceptor strength for constructing red TADF emitters with satisfactory CIE coordinates and high $\Phi_{\mathrm{PL}} \mathrm{s}$.

In this study, we integrated two cyanobenzene groups into the dipyrido[3,2-a: $\left.2^{\prime}, 3^{\prime}-\mathrm{c}\right]$ phenazine core to construct a new electron acceptor moiety, 3,6-DCNB-DPPZ. Combining with two triphenylamine donors in the D-A-D motif, we designed and synthesized a red TADF molecule, 4,4'-(11,12-bis(4-(diphenylamino)phenyl)dipyrido[3,2-a:2', $3^{\prime}$-c]-phenazine3,6-diyl)dibenzonitrile (3,6_R). Benefiting from the high-rigidity molecular skeleton and strong CT transition between the electron donor and accept-or unit, 3,6_R exhibited a satisfactory red emission peaking at above $610 \mathrm{~nm}$, together with a high $\Phi_{\mathrm{PL}}$ of $86 \%$ and the impressive external quantum efficiency of $12 \%$.

\section{Results and Discussion}

As depicted in Scheme 1, the target compound of 3,6_R was synthesized in two steps. The key intermediate of 3,6_Br was synthesized via a dehydration cyclization reaction using $N^{4}, N^{4}, N^{4 \prime \prime}, N^{4 \prime \prime}$-tetraphenyl-[1, $1^{\prime}: 2^{\prime}, 1^{\prime \prime}$-terphenyl]-4,4 $4^{\prime}, 4^{\prime \prime}, 5^{\prime}$-tetraamine and 2,9-dibromo4a,6a-dihydro-1,10-phenanthroline-5,6-dione (Scheme S1). Afterward, the target compound 3,6_R was synthesized by a palladium catalyzed Suzuki-Miyaura cross-coupling reaction of 3,6_Br with 4-(4,4,5,5-tetramethyl-1,3,2-dioxaborolan-2-yl)benzonitrile in a good yield (Scheme 1). The key intermediate and target compound were characterized and confirmed via ${ }^{1} \mathrm{H}-\mathrm{NMR}$ spectroscopy (Figures S3 and S4 in Supplementary Materials), high-resolution mass spectrometry (HRMS) (Figure S5), and elemental analysis.
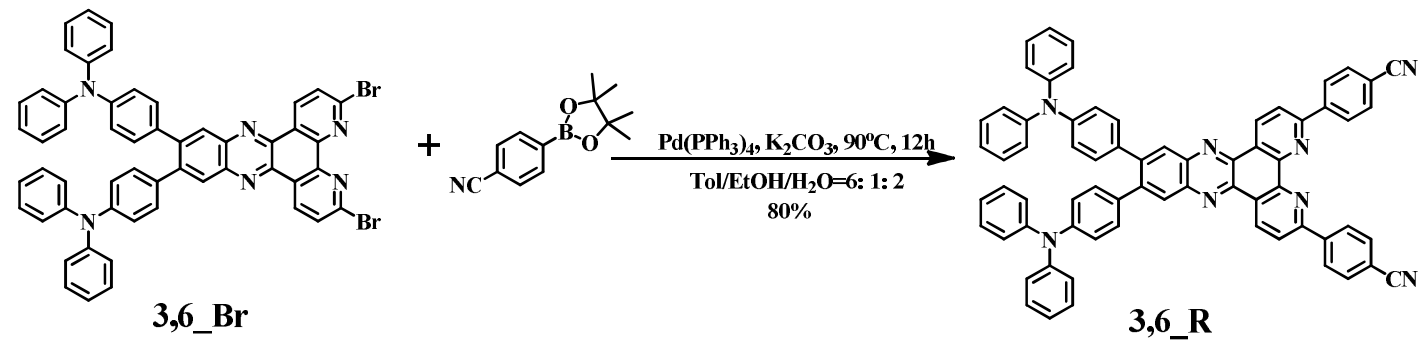

Scheme 1. Synthetic route of 3,6_R.

Theoretical calculations based on density functional theory (DFT) and time-dependent DFT (TD-DFT) were carried out on the molecule to predict its molecular characteristics and energy levels. The optimized ground state structure (Figure S1) revealed that 3,6_R had relatively high dihedral angles of 50-63 between the TPA donor and the 3,6-DCNB-DPPZ acceptor core. This guarantees well-separated frontier molecular orbital distributions for the molecule (Figure 1), together with the HOMO and LUMO mainly located on the TPA donor and the 3,6-DCNB-DPPZ acceptor core, respectively. Furthermore, 3,6_R had a small torsion angle of $10^{\circ}$ between the cyanobenzene acceptor subunit and the DPPZ core. Such planar acceptor structure of 3,6-DCNB-DPPZ leads to some degree of LUMO distribution on the cyanobenzene acceptor subunit for 3,6_R. Accordingly, the delocalized conjugation in the 3,6-DCNB-DPPZ acceptor made 3,6_R have a deepened LUMO level of $-3.02 \mathrm{eV}$. This result suggests that the 3,6-DCNB-DPPZ acceptor has strong acceptor strength. 3,6_R had relatively low $\mathrm{S}_{1} / \mathrm{T}_{1}$ energies of $2.22 / 2.01 \mathrm{eV}$, which can be attributed to the strong CT transition from the TPA donor to the 3,6-DCNB-DPPZ acceptor. Accordingly, 3,6_R had a small $\Delta \mathrm{E}_{\mathrm{ST}}$ value of $0.21 \mathrm{eV}$, favorable to access a TADF channel. The natural transition orbitals (NTOs) (Figure S2) on excited states revealed that the $S_{1}$ of 3,6_R had intramolecular CT character; while its $\mathrm{T}_{1}$ possessed $\mathrm{CT} /$ locally excited (LE) hybrid NTO 
distributions. The different NTO natures of $S_{1}$ and $T_{1}$ may benefit up-conversion process from $\mathrm{T}_{1}$ to $\mathrm{S}_{1}$ according to the El-Sayed rule [32].

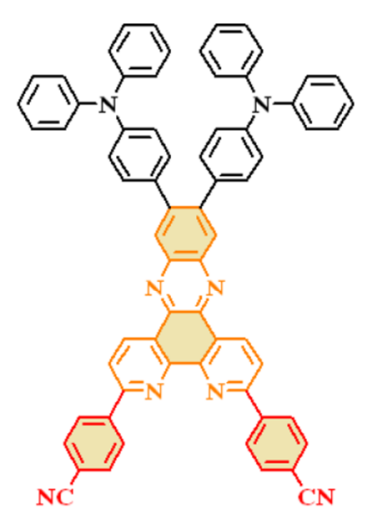

3,6_R

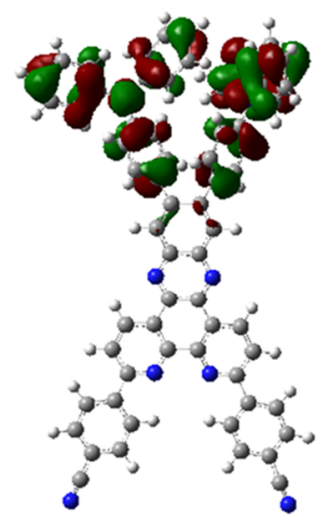

HOMO

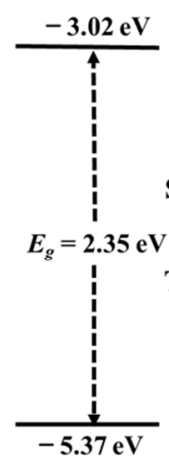

$-5.37 \mathrm{eV}$

Figure 1. Molecular structure, frontier molecular orbital distributions and energy levels of lowest-lying singlet and triplet excited states of 3,6_R obtained by theoretical calculations.

The thermal stability of the compound was investigated by thermo-gravimetric analysis (TGA) and differential scanning calorimetry (DSC) measurements. As shown in Figure $2 \mathrm{a}$, the decomposition temperature $\left(\mathrm{T}_{\mathrm{d}}\right.$ with a $5 \mathrm{wt} \%$ loss) of 3,6_R was determined as high as $555{ }^{\circ} \mathrm{C}$. Apparently, the planar and rigid structure endows 3,6_R with pretty good thermal stability. Furthermore, no clear glass transition temperature was observed in the DSC curve, which could be associated with high molecular rigidity of the compound. These results implied that the compound had excellent thermal stability and thus could be suitable for vacuum deposition.

(a)

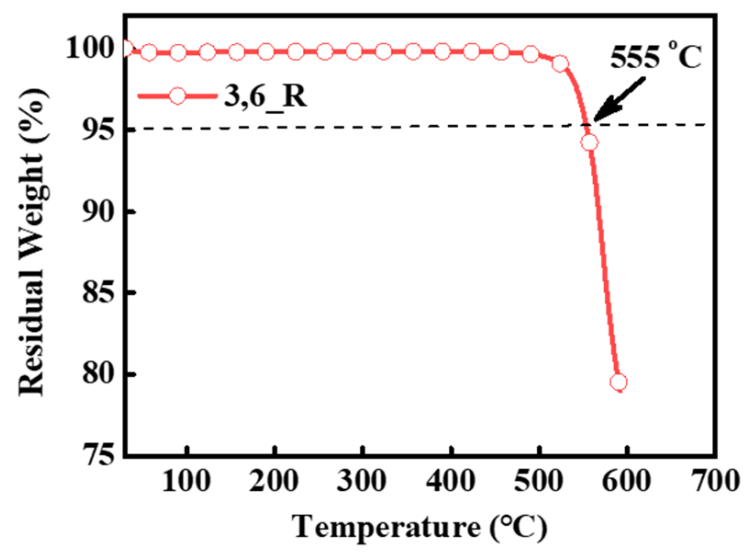

(b)

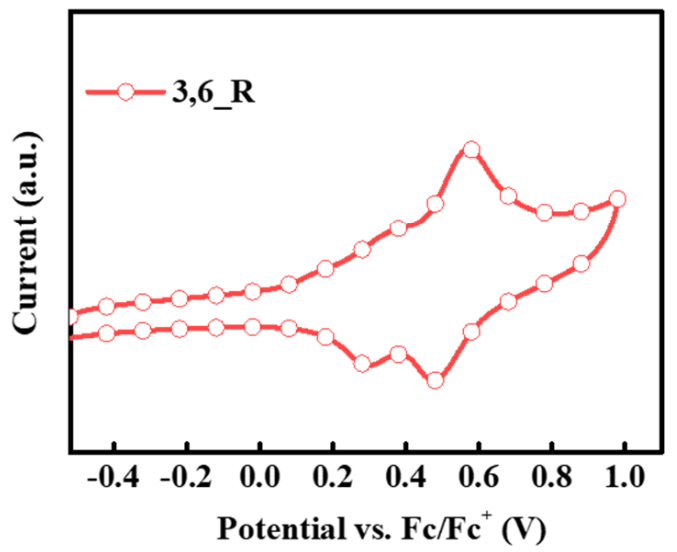

Figure 2. (a) TGA curve of 3,6_R. (b) Oxidation behavior of 3,6_R.

The electrochemical properties of the compound were tested by cyclic voltammetry using ferrocenium/ferrocene as an internal reference. As shown in Figure 2b, the compound experienced a quasi-reversible oxidation process at $+0.55 \mathrm{~V}$ (calibrated versus ferrocenium/ferrocene) assigned to the triphenylamine donor. Furthermore, the HOMO energy level of 3,6_R was determined to be $-5.32 \mathrm{eV}$, according to half-wave potential. As calculated from the difference between the HOMO level and the optical band gap $\left(E_{g}\right)$, the LUMO energy level of 3,6_R was calculated to be $-3.06 \mathrm{eV}$. These results are basically consistent with the abovementioned theoretical results. 
The UV-Vis absorption and fluorescence spectra of 3,6_R in $10^{-5} \mathrm{M}$ toluene was shown in Figure 3a. 3,6_R had a strong absorption band at $355 \mathrm{~nm}$ (Table 1), which can be assigned to $\pi-\pi^{*}$ transition of the LE state of DPPZ-BCN moiety. Weak and broad absorption band at $480 \mathrm{~nm}$ for the compound was recognized as typical CT transition from the TPA donor to the 3,6-DCNB-DPPZ acceptor. Moreover, 3,6_R displayed a strong and structureless orange-red emission with a main emission peak at $571 \mathrm{~nm}$ in dilute toluene solution. Furthermore, 3,6_R exhibited a significant positive solvatochromic effect with a remarkable redshift of $90 \mathrm{~nm}$ when varying the solvent from low-polarity toluene to highpolarity dichloromethane (Figure S6). This strongly suggests obvious CT characteristic of $S_{1}$ for the emitter. Subsequently, the emissive characteristics of the emitter in the film state was also studied by employing a widely used phosphine oxide host matrix of bis(2(diphenylphosphino)phenyl)ether oxide (DPEPO). 3,6_R in the DPEPO host displayed CT-featured emission profile with a main emission peak at $613 \mathrm{~nm}$ at room temperature. Moreover, its phosphorescence spectrum in the DPEPO films at a low temperature of $77 \mathrm{~K}$ was dominant by structureless and broad emission profile derived from the typical CT transition of $\mathrm{T}_{1}$. On the basis of onset wavelengths of fluorescence and phosphorescence spectra, 3,6_R had low $\mathrm{S}_{1} / \mathrm{T}_{1}$ levels of $2.28 / 2.06 \mathrm{eV}$, respectively, which can be rationalized by the strong CT transition from the TPA donor to the 3,6-DCNB-DPPZ acceptor. Accordingly, 3,6_R in the DPEPO host had a small $\triangle \mathrm{E}_{\mathrm{ST}}$ value of $0.22 \mathrm{eV}$, in good consistence with the theoretical results. The small $\Delta \mathrm{E}_{\mathrm{ST}}$ value could access the TADF process for the emitter in the film state.

(a)

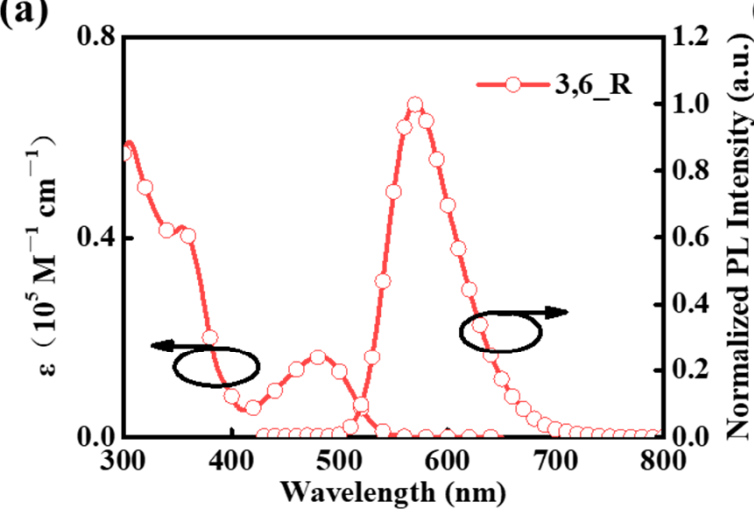

(c)

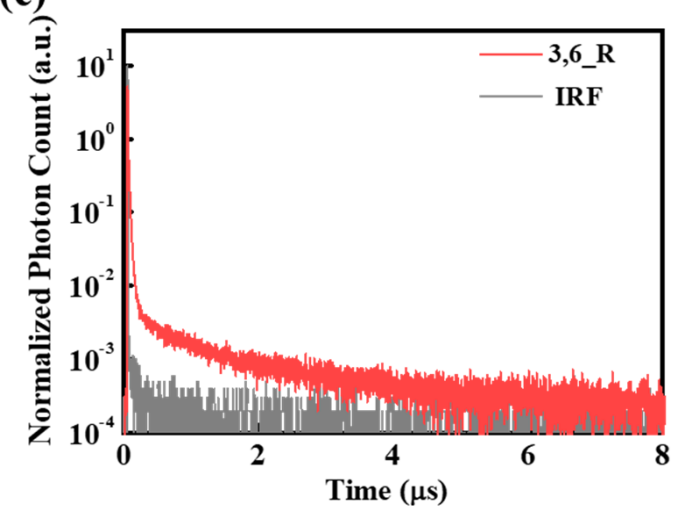

(b)

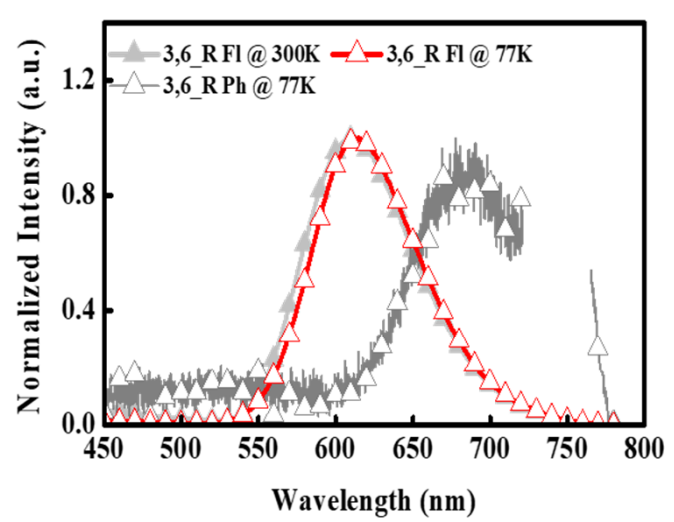

(d)

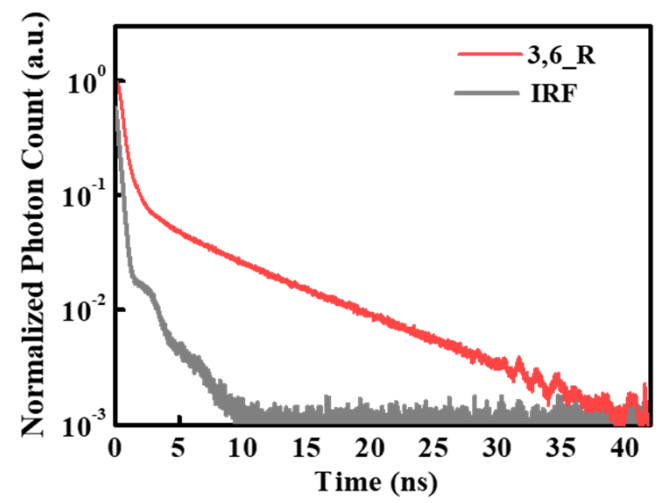

Figure 3. (a) UV-Vis absorption and normalized PL spectra of 3,6_R in $10^{-5} \mathrm{M}$ toluene solution at $300 \mathrm{~K}$. (b) Normalized fluorescence (measured at 300 and $77 \mathrm{~K}$ ) and phosphorescence spectra (measured at $77 \mathrm{~K}$ ) of $10 \mathrm{wt} \%$ 3,6_R doped into the DPEPO host. (c) Transient photoluminescence decay curves of $10 \mathrm{wt} \%$ 3,6_R doped into the DPEPO host. (d) The prompt fluorescence decay of $10 \mathrm{wt} \%$ 3,6_R doped into the DPEPO film. 
Table 1. Photophysical properties of 3,6_R.

\begin{tabular}{ccccccc}
\hline Compound & $\begin{array}{c}\lambda_{\text {abs }} \\
{[\mathbf{n m}]^{\mathbf{a}}}\end{array}$ & $\begin{array}{c}\lambda_{\text {em }} \\
{[\mathbf{n m}]^{\mathbf{b}}}\end{array}$ & $\begin{array}{c}\boldsymbol{\tau}_{\mathrm{p}} / \boldsymbol{\tau}_{\mathrm{d}} \\
{[\mathbf{n s}] /[\mu \mathbf{s}]^{\mathbf{c}}}\end{array}$ & $\begin{array}{c}\boldsymbol{\Phi}_{\mathbf{p}} / \boldsymbol{\Phi}_{\mathbf{d}} \\
{[\%]^{\mathbf{d}}}\end{array}$ & $\begin{array}{c}\boldsymbol{\Phi}_{\mathrm{PL}} \\
{[\%]^{\mathbf{e}}}\end{array}$ & $\begin{array}{c}k_{\mathrm{r}, \mathrm{S}} / k_{\mathrm{RISC}} \\
{\left[\mathbf{1 0}^{\mathbf{7}} \mathbf{s}^{-\mathbf{1}}\right]^{\mathbf{f}}}\end{array}$ \\
\hline $3,6 \_\mathrm{R}$ & $355 / 480$ & $571 / 613$ & $20 / 1.04$ & $72 / 14$ & 86 & $3.6 / 0.067$ \\
\hline
\end{tabular}

${ }^{a}$ Measured in $10^{-5} \mathrm{M}$ toluene solution. ${ }^{\mathrm{b}}$ Measured in $10^{-5} \mathrm{M}$ toluene solution and in DPEPO film with $10 \mathrm{wt} \%$ doping concentration. ${ }^{\mathrm{c}}$ Measured in $10 \mathrm{wt} \%$ DPEPO-doped film. ${ }^{\mathrm{d}}$ The prompt and delayed fluorescence photoluminescence quantum yield of $10 \mathrm{wt} \%$ 3,6_R doped into DPEPO film under oxygen-free condition. ${ }^{\mathrm{e}}$ The rate constants of radiative singlet excitons and RISC process of $10 \mathrm{wt} \% 3,6 \_\mathrm{R}$ doped into DPEPO film. ${ }^{\mathrm{f}}$ Radiation transition rate constants and reverse intersystem crossing (RISC) rate constants of 10 wt $\%$ 3,6_R doped into DPEPO film.

To confirm TADF character, we further measured the transient PL decay curves of 3,6_R in the DPEPO host. As shown in Figure 3c,d, the transient PL decays of 3,6_R experienced double exponential decays composed of prompt and delayed fluorescence components together with the fitting lifetimes of $20 \mathrm{~ns}$ and $1.04 \mu \mathrm{s}$. Such a short delayed fluorescence lifetime of $\sim 1 \mu \mathrm{s}$ manifested that efficient RISC from $T_{1}$ to $S_{1}$ occurred in the emitter and thus efficient utilization of triplet excitons could be expected in photo- and electroluminescence process. Thanks to high rigidity in the molecular skeleton, 3,6_R in the DPEPO host had a high $\Phi_{\mathrm{PL}}$ of $86 \%$. To better understand the emissive processes of the emitter, the corresponding rate constant of radiative transition $\left(k_{r, S}\right)$ and RISC $\left(k_{R I S C}\right)$ were calculated using related equations (Equations S1-6 in the supporting information). 3,6_R had a moderate $k_{\text {RISC }}$ of $6.7 \times 10^{5} \mathrm{~s}^{-1}$ (Table 1 and Table S2), on par with typical TADF emitters. Moreover, the emitter possessed high $k_{r, S}$ of $3.6 \times 10^{7} \mathrm{~s}^{-1}, 6.1$-fold larger than its corresponding nonradiative rate constant. Such a high rate constant of radiative transition and RISC process implied that 3,6_R can efficiently harvest most excitons in the emissive process. This may be beneficial to obtain good device performance in the OLEDs.

To evaluate electroluminescence properties of 3,6_R, the doped devices with a typical configuration (Figures $4 \mathrm{a}$ and S8) were fabricated. It was ITO/HAT-CN (5 nm)/TAPC $(30 \mathrm{~nm}) / \mathrm{mCP}(10 \mathrm{~nm}) / \mathrm{DPEPO}: 3,6 \_\mathrm{R}(10$ or $30 \mathrm{wt} \%, 20 \mathrm{~nm}) / \mathrm{DPEPO}(10 \mathrm{~nm}) / \mathrm{TmPyPB}$ $(30 \mathrm{~nm}) / \mathrm{Liq}(1.5 \mathrm{~nm}) / \mathrm{Al}(100 \mathrm{~nm})$. ITO (indium tin oxide) and $\mathrm{Al}$ acted as anode and cathode, respectively. HAT-CN (1,4,5,8,9,11-hexaazatriphenylene-hexanitrile) and Liq (8-hydroxyquinolinato lithium) were used as the hole- and electron-injecting layer, respectively. TAPC (1,1-bis[(di-4-tolylamino)phenyl]cyclohexane) and TmPyPB (1,3,5-tri(m-pyrid3-yl-phenyl)benzene) functioned as hole- and electron-transporting layer, respectively. $\mathrm{mCP}(1,3$-carbazolbenze-ne) and DPEPO acted as exciton-blocking layers, respectively; 3,6_R was doped into the DPEPO host material with the doping concentrations of $10 \mathrm{wt} \%$ (device A) and $30 \mathrm{wt} \%$ (device B) to serve as the emissive layers, respectively. The energy level diagram and corresponding molecular structures of devices $A$ and $B$ were shown in Figures $4 \mathrm{a}$ and $\mathrm{S} 8$.

Electroluminescence (EL) characteristics of the 3,6_R-based OLEDs are shown in Figure $4 \mathrm{~b}-\mathrm{d}$ and the key EL data were summarized in Table 2. Similar to the PL spectra in the DPEPO host, device A displayed a red EL profile peaking at $619 \mathrm{~nm}$, together with favorable CIE coordinates of $(0.62,0.38)$. With the increasing doping concentration from 10 to $30 \mathrm{wt} \%$, the EL peak wavelength red-shifted to $629 \mathrm{~nm}$ for device B, corresponding to CIE coordinates of $(0.64,0.36)$. Meanwhile, no detectable host emission peaking at the range of 370-450 nm was observed for both devices, suggesting excellent exciton confinement in the emitter 3,6_R. Both devices exhibited similar current density-voltage-luminance characteristics with the same turn-on voltages of $\sim 4.0 \mathrm{~V}$. Thanks to the high PLQY of $86 \%$, 3,6_R supported its devices with outstanding EL performance. The optimal device A delivered a maximum external quantum efficiency of $12.0 \%$, a maximum current efficiency of $15.3 \mathrm{~cd} \mathrm{~A}^{-1}$, and a maximum power efficiency of $12.0 \mathrm{~lm} \mathrm{~W}^{-1}$. The non-ideal device performance could be associated with the relatively weak triplet harvesting ability of 3,6_R in the EL process originating from its low delayed fluorescence ratio of $14 \%$ and moderate $k_{\text {RISC. }}$. 
(a)
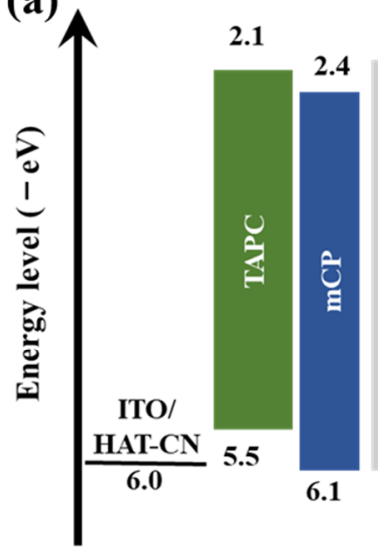

2.0

2.0

(c)

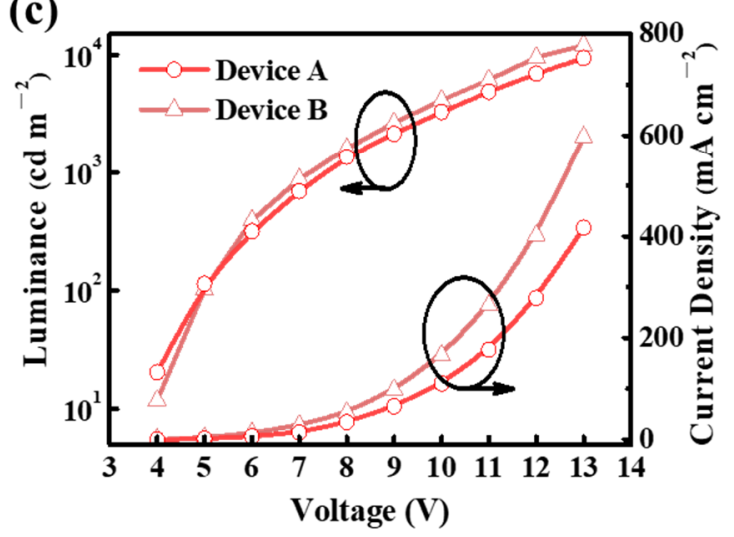

(b)

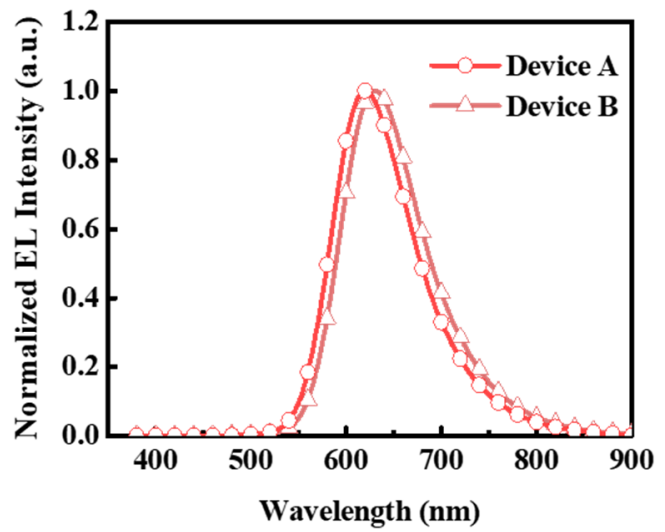

(d)

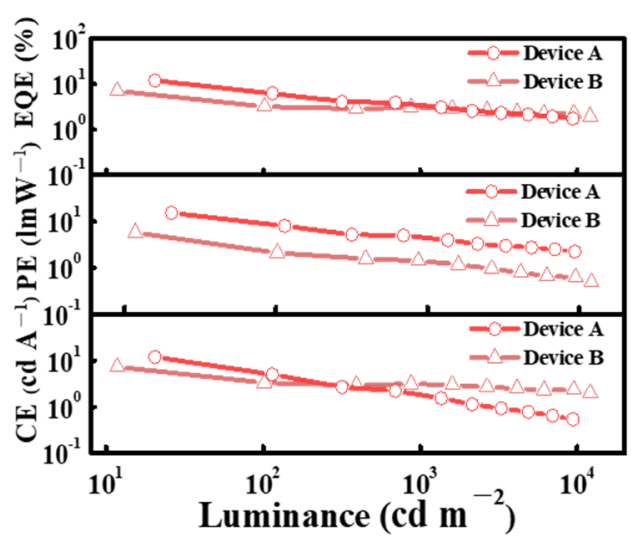

Figure 4. (a) The energy level diagrams of devices A and B. (b) Electroluminescence spectra of devices A and B. (c) Luminance-voltage-current density curves of devices A and B. (d) External quantum efficiency, power efficiency, and current efficiency as a function of luminance for devices A and B.

Table 2. Electroluminescence characteristics of the devices.

\begin{tabular}{|c|c|c|c|c|c|c|c|}
\hline Devices & $\mathrm{V}_{\text {on }}[\mathrm{V}]^{\mathrm{a}}$ & $\lambda_{\mathrm{EL}}[\mathrm{nm}]^{b}$ & 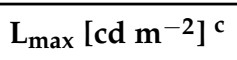 & $C E\left[c d A^{-1}\right]^{d}$ & $P E\left[\operatorname{lm} W^{-1}\right]^{e}$ & $\operatorname{EQE}[\%]^{\mathrm{f}}$ & $\operatorname{CIE}(x, y)^{g}$ \\
\hline A & 4.0 & 619 & 9382 & $15.3 / 5.5 / 1.9$ & $12.0 / 8.7 / 4.5$ & $12.0 / 6.6 / 3.5$ & $(0.62,0.38)$ \\
\hline B & 4.0 & 629 & 12100 & $7.4 / 2.1 / 1.4$ & $5.8 / 3.6 / 3.2$ & $7.1 / 3.2 / 3.0$ & $(0.64,0.36)$ \\
\hline
\end{tabular}

${ }^{a}$ The turn on voltage at the luminance of above $1 \mathrm{~cd} \mathrm{~m}^{-2} .{ }^{\mathrm{b}}$ EL peak of the devices. ${ }^{\mathrm{c}}$ Maximum luminance of the devices. ${ }^{\mathrm{d}}$ Current efficiency at maximum, 100 , and $1000 \mathrm{~cd} \mathrm{~m}^{-2}$. e Power efficiency at maximum, 100 , and $1000 \mathrm{~cd} \mathrm{~m}^{-2} .{ }^{\mathrm{f}}$ External quantum efficiency at maximum, 100, and $1000 \mathrm{~cd} \mathrm{~m}^{-2}$. g Commission Internationale de l'Eclairage (CIE) coordinates.

\section{Materials and Methods}

Synthesis of 4,4'-(11,12-bis(4-(diphenylamino)phenyl)dipyrido[3,2-a:2', $3^{\prime}$-c]phena-zine3,6-diyl)dibenzonitrile (3,6_R)

$\mathrm{Pd}\left(\mathrm{PPh}_{3}\right)_{4}(20 \mathrm{mg}, 0.02 \mathrm{mmol}), \mathrm{K}_{2} \mathrm{CO}_{3}(829 \mathrm{mg}, 6.00 \mathrm{mmol}), 4-(4,4,5,5$-tetramethyl-1,3,2dioxaborolan-2-yl)benzonitrile (122 mg, $0.54 \mathrm{mmol}), 4$,4'-(3,6-dibromodipyrido[3,2-a:2', $3^{\prime}$ c]phenazine-11,12-diyl)bis( $N, N$-diphenylaniline) $\left(3,6 \_B r, 200 \mathrm{mg}, 0.22 \mathrm{mmol}\right)$ in a mixed solvent containing $12 \mathrm{~mL}$ toluene, $2 \mathrm{~mL}$ ethanol, and $4 \mathrm{~mL}$ water were stirred overnight at $90{ }^{\circ} \mathrm{C}$ under argon atmosphere. Afterwards, the reaction mixture was poured into $200 \mathrm{~mL}$ water, extracted with dichloromethane for three times, dried over with anhydrous $\mathrm{Na}_{2} \mathrm{SO}_{4}$. After the removal of solvents, the residue was purified using column chromatography with dichloromethane/ethyl acetate $(4: 1 \mathrm{v} / \mathrm{v})$ as the eluent to give a red powder $(168 \mathrm{mg}$, yield: $80 \%) .{ }^{1} \mathrm{H}-\mathrm{NMR}\left(400 \mathrm{MHz}, \mathrm{CDCl}_{3}+\mathrm{TMS}, 25^{\circ} \mathrm{C}\right): \delta 9.72(\mathrm{~d}, J=8.4 \mathrm{~Hz}, 2 \mathrm{H}), 8.56(\mathrm{~d}$, $J=8.4 \mathrm{~Hz}, 4 \mathrm{H}), 8.36(\mathrm{~s}, 2 \mathrm{H}), 8.29(\mathrm{~d}, J=8.2 \mathrm{~Hz}, 2 \mathrm{H}), 7.91(\mathrm{~d}, J=8.3 \mathrm{~Hz}, 4 \mathrm{H}), 7.31-7.28(\mathrm{~m}$, $8 \mathrm{H}), 7.22(\mathrm{~d}, J=8.5 \mathrm{~Hz}, 4 \mathrm{H}), 7.15(\mathrm{~d}, J=7.6 \mathrm{~Hz}, 8 \mathrm{H}), 7.09-7.04(\mathrm{~m}, 8 \mathrm{H})$. Elemental analysis 
(\%) for $\mathrm{C}_{68} \mathrm{H}_{42} \mathrm{~N}_{8}$ : $\mathrm{C}, 84.10 ; \mathrm{H}, 4.36$; $\mathrm{N}, 11.54$; found: $\mathrm{C}, 84.17 ; \mathrm{H}, 4.46 ; \mathrm{N}, 11.67$. HRMS (ESI) $m / z$ calcd for $\mathrm{C}_{68} \mathrm{H}_{42} \mathrm{~N}_{8} \mathrm{Na}^{+}[\mathrm{M}+\mathrm{Na}]^{+}$993.3424, found 993.3421.

\section{Conclusions}

In summary, we have constructed a new electron acceptor unit of 3,6-DCNB-DPPZ by introducing two cyanobenzene groups into 3,6-positions of dipyrido[3,2-a:2', $3^{\prime}$-c]phenazine unit and further designed and synthesized the red emitter of 3,6_R by combining this rigid electron acceptor with two triphenylamine donors. Thanks to the strong charge transfer transition and high molecular rigidity, 3,6_R had good thermal stability, satisfactory red emission, high photoluminescence quantum yield, and distinct TADF nature with short delayed fluorescence lifetime. Based on these excellent properties, the 3,6_R-based device delivered good electroluminescence performance with the maximum external quantum efficiency of $12.0 \%$, together with an emissive peak at $619 \mathrm{~nm}$ and corresponding CIE coordinates of $(0.62,0.38)$. This finding presents a feasible pathway for constructing efficient red-emitting TADF emitters on the basis of newly designed electron acceptors. Further studies on deep-red/near-infrared TADF emitters bearing new electron acceptors are ongoing.

Supplementary Materials: The following are available online: computational methods; details for device fabrications and measurements; key intermediate synthesis route (Scheme S1); optimal geometric construction (Figure S1); NTOs (Figure S2); physical properties and rate constants (Tables S1 and S2); ${ }^{1} \mathrm{H}-\mathrm{NMR}$ spectroscopy of key intermediate and target compound (Figures S3 and S4); HRMS (ESI) (Figure S5); solvents polarization effect (Figure S6); chemical structures of the materials employed in the vacuum-deposited devices (Figure S7).

Author Contributions: L.H. performed the syntheses, structural characterizations, spectroscopic measurements of the compound and wrote the draft of the manuscript. X.Z. fabricated and tested the OLEDs. W.N. and A.Y. performed the DFT calculations. S.G. conceived, designed and guided the project. S.G. and A.Y. performed writing-review and editing. S.G. funded the project. Y.L. provided resources. All authors have read and agreed to the published version of the manuscript.

Funding: This research was supported by the National Natural Science Foundation of China (grant number: 51873158) and the Shenzhen Science and Technology Program (grant number: JCYJ20190808151209557).

Institutional Review Board Statement: Not applicable.

Informed Consent Statement: Not applicable.

Data Availability Statement: The data presented in this study are available on request from the corresponding author.

Acknowledgments: The numerical calculations in this paper have been done on the supercomputing system in the Supercomputing Center of Wuhan University.

Conflicts of Interest: The authors declare no conflict of interest.

Sample Availability: Samples of the compounds are available from the corresponding author. However, it may be necessary to pay properly for the synthesis and mailing of samples.

\section{References}

1. Uoyama, H.; Goushi, K.; Shizu, K.; Nomura, H.; Adachi, C. Highly efficient organic light emitting diodes from dela-yed fluorescence. Nature 2012, 492, 234-238. [CrossRef]

2. Tao, Y.; Yuan, K.; Chen, T.; Xu, P.; Li, H.; Chen, R.; Zheng, C.; Zhang, L.; Huang, W. Thermally activated delayed fluorescence materials towards the breakthrough of organoelectronics. Adv. Mater. 2014, 26, 7931-7958. [CrossRef]

3. Yang, Z.; Mao, Z.; Xie, Z.; Zhang, Y.; Liu, S.; Zhao, J.; Xu, J.; Chi, Z.; Aldred, M.P. Recent advances in organic the-rmally activated delayed fluorescence materials. Chem. Soc. Rev. 2017, 46, 915-1016. [CrossRef]

4. Liu, Y.; Li, C.; Ren, Z.; Yan, S.; Bryce, M.R. All-organic thermally activated delayed fluorescence materials for organ-ic lightemitting diodes. Nat. Rev. Mater. 2018, 3, 1038-1058. [CrossRef]

5. Wong, M.Y.; Zysman-Colman, E. Purely organic thermally activated delayed fluorescence materials for organic light-emitting diodes. Adv. Mater. 2017, 29, 1605444. [CrossRef] [PubMed] 
6. Cui, L.-S.; Gillett, A.J.; Zhang, S.-F.; Ye, H.; Liu, Y.; Chen, X.-K.; Lin, Z.-S.; Evans, E.W.; Myers, W.K.; Ronson, T.K.; et al. Fast spin-flip enables efficient and stable organic electroluminescence from charge-transfer states. Nat. Photon. 2020, 14, 636-642. [CrossRef]

7. Wada, Y.; Nakagawa, H.; Matsumoto, S.; Wakisaka, Y.; Kaji, H. Organic light emitters exhibiting very fast reverse i-ntersystem crossing. Nat. Photon. 2020, 14, 643-649. [CrossRef]

8. Wu, K.; Zhang, T.; Wang, Z.; Wang, L.; Zhan, L.; Gong, S.; Zhong, C.; Lu, Z.-H.; Zhang, S.; Yang, C. De novo des-ign of excited-state intramolecular proton transfer emitters via a thermally activated delayed fluorescence channel. J. Am. Chem. Soc. 2018, 140, 8877-8886. [CrossRef]

9. Yang, M.; Park, I.S.; Yasuda, T. Full-color, narrowband, and high-efficiency electroluminescence from boron and carb-azole embedded polycyclic heteroaromatics. J. Am. Chem. Soc. 2020, 142, 19468-19472. [CrossRef] [PubMed]

10. Ahn, D.; Kim, S.; Lee, H.; Ko, I.; Karthik, D.; Lee, J.; Kwon, J.H. Highly efficient blue thermally activated delayed f-luorescence emitters based on symmetrical and rigid oxygen-bridged boron acceptors. Nat. Photon. 2019, 13, 540-546. [CrossRef]

11. Lin, T.-A.; Chatterjee, T.; Tsai, W.-L.; Lee, W.-K.; Wu, M.-J.; Jiao, M.; Pan, K.-C.; Yi, C.-L.; Chung, C.-L.; Wong, K.-T.; et al. Sky-blue organic light emitting diode with $37 \%$ external quantum efficiency using thermally activated dela-yed fluorescence from spiroacridine-triazine hybrid. Adv. Mater. 2016, 28, 6976-6983. [CrossRef]

12. Xiang, Y.; Li, P.; Gong, S.; Huang, Y.-H.; Wang, C.-Y.; Zhong, C.; Zeng, W.; Chen, Z.; Lee, W.-K.; Yin, X.; et al. Ac-ceptor plane expansion enhances horizontal orientation of thermally activated delayed fluorescence emitter. Sci. Adv. 2020, 6, eaba7855. [CrossRef] [PubMed]

13. Zhang, Y.; Zhang, D.; Wei, J.; Liu, Z.; Lu, Y.; Duan, L. Multi-resonance induced thermally activated delayed fluoro-phores for narrowband green OLEDs. Angew. Chem. Int. Ed. 2019, 58, 16912-16917. [CrossRef] [PubMed]

14. Wu, T.-L.; Huang, M.-J.; Lin, C.-C.; Huang, P.-Y.; Chou, T.-Y.; Chen-Cheng, R.-W.; Lin, H.-W.; Liu, R.-S.; Cheng, C.-H. Diboron compound-based organic light-emitting diodes with high efficiency and reduced efficiency roll-off. Nat. Photon. 2018, 12, 235-240. [CrossRef]

15. Zhang, Y.-L.; Ran, Q.; Wang, Q.; Liu, Y.; Hänisch, C.; Reineke, S.; Fan, J.; Liao, L.-S. High-efficiency red organic lig-ht-emitting diodes with external quantum efficiency close to $30 \%$ based on a novel thermally activated delayed fluo-rescence emitter. Adv. Mater. 2019, 31, 1902368. [CrossRef] [PubMed]

16. Xue, J.; Liang, Q.; Wang, R.; Hou, J.; Li, W.; Peng, Q.; Shuai, Z.; Qiao, J. Highly efficient thermally activated delay-ed fluorescence via J-aggregates with strong intermolecular charge transfer. Adv. Mater. 2019, 31, 1808242. [CrossRef]

17. Zeng, W.; Zhou, T.; Ning, W.; Zhong, C.; He, J.; Gong, S.; Xie, G.; Yang, C. Realizing 22.5\% external quantum effic-iency for solution-processed thermally activated delayed-fluorescence OLEDs with red emission at $622 \mathrm{~nm}$ via a syn-ergistic strategy of molecular engineering and host selection. Adv. Mater. 2019, 31, 1901404. [CrossRef]

18. Zhang, Q.; Kuwabara, H.; Potscavage, W.J.; Huang, S.; Hatae, Y.; Shibata, T.; Adachi, C. Anthraquinone-based intra-molecular charge-transfer compounds: Computational molecular design, thermally activated delayed fluorescence, and highly efficient red electroluminescence. J. Am. Chem. Soc. 2014, 136, 18070. [CrossRef]

19. Kim, J.H.; Yun, J.H.; Lee, J.Y. Recent progress of highly efficient red and near-infrared thermally activated delayed fluorescent emitters. Adv. Opt. Mater. 2018, 6, 1800255. [CrossRef]

20. Chen, J.-X.; Tao, W.-W.; Chen, W.-C.; Xiao, Y.-F.; Wang, K.; Cao, C.; Yu, J.; Li, S.; Geng, F.-X.; Adachi, C.; et al. Re-d/Near-infrared thermally activated delayed fluorescence OLEDs with near $100 \%$ internal quantum efficiency. Angew. Chem. Int. Ed. 2019, 58, 14660-14665. [CrossRef] [PubMed]

21. Li, C.; Duan, R.; Liang, B.; Han, G.; Wang, S.; Ye, K.; Liu, Y.; Yi, Y.; Wang, Y. Deep-red to near-infrared thermally activated delayed fluorescence in organic solid films and electroluminescent devices. Angew. Chem. Int. Ed. 2017, 56, 11525-11529. [CrossRef]

22. Gong, X.; Lu, C.-H.; Lee, W.-K.; Li, P.; Huang, Y.-H.; Chen, Z.; Zhan, L.; Wu, C.-C.; Gong, S.; Yang, C. High-efficie-ncy red thermally activated delayed fluorescence emitters based on benzothiophene-fused spiro-acridine donor. Chem. Eng. J. 2021, 405, 126663. [CrossRef]

23. Wang, H.; Zhao, B.; Ma, P.; Li, Z.; Wang, X.; Zhao, C.; Fan, X.; Tao, L.; Duan, C.; Zhang, J.; et al. A red thermally activated delayed fluorescence emitter employing dipyridophenazine with a gradient multi-induct-ive effect to impr-ove radiation efficiency. $J$. Mater. Chem. C 2019, 7, 7525-7530. [CrossRef]

24. Chen, J.-X.; Wang, K.; Zheng, C.-J.; Zhang, M.; Shi, Y.-Z.; Tao, S.-L.; Lin, H.; Liu, W.; Tao, W.-W.; Ou, X.-M.; et al. Red organic light-emitting diode with external quantum efficiency beyond $20 \%$ based on a novel thermally activated delayed fluorescence emitter. Adv. Sci. 2018, 5, 1800436. [CrossRef]

25. Jin, J.; Wang, W.; Xue, P.; Yang, Q.; Jiang, H.; Tao, Y.; Zheng, C.; Xie, G.; Huang, W.; Chen, R. Intermolecular locking design of red thermally activated delayed fluorescence molecules for high-performance solution-processed organic light-emitting diodes. $J$. Mater. Chem. C 2021, 9, 2291-2297. [CrossRef]

26. Wang, S.; Yan, X.; Cheng, Z.; Zhang, H.; Liu, Y.; Wang, Y. Highly efficient near-infrared delayed fluorescence orga-nic light emitting diodes using a phenanthrene-based charge-transfer compound. Angew. Chem. Int. Ed. 2015, 54, 13068-13072. [CrossRef] [PubMed]

27. Li, J.; Nakagawa, T.; MacDonald, J.; Zhang, Q.; Nomura, H.; Miyazaki, H.; Adachi, C. Highly efficient organic light-emitting diode based on a hidden thermally activated delayed fluorescence channel in a heptazine derivative. Adv. Mater. 2013, 25, 3319-3323. [CrossRef] [PubMed] 
28. Furue, R.; Matsuo, K.; Ashikari, Y.; Ooka, H.; Amanokura, N.; Yasuda, T. Highly efficient red-orange delayed fluore-scence emitters based on strong $\pi$-accepting dibenzophenazine and dibenzoquinoxaline cores: Toward a rational pur-ered OLED design. Adv. Opt. Mater. 2018, 6, 1701147. [CrossRef]

29. Kothavale, S.; Chung, W.J.; Lee, J.Y. Rational molecular design of highly efficient yellow-red thermally activated del-ayed fluorescent emitters: A combined effect of auxiliary fluorine and rigidified acceptor unit. ACS Appl. Mater. Interfaces 2020, 12, 18730-18738. [CrossRef]

30. Balijapalli, U.; Nagata, R.; Yamada, N.; Nakanotani, H.; Tanaka, M.; D’Aléo, A.; Placide, V.; Mamada, M.; Tsuchiya, Y.; Adachi, C. Highly efficient near-infrared electrofluorescence from a thermally-activated delayed fluorescence mole-cule. Angew. Chem. Int. Ed. 2021, 60, 8477-8482. [CrossRef]

31. Gong, X.; Li, P.; Huang, Y.-H.; Wang, C.-Y.; Lu, C.-H.; Lee, W.-K.; Zhong, C.; Chen, Z.; Ning, W.; Wu, C.-C.; et al. A red thermally activated delayed fluorescence emitter simultaneously having high photoluminescence quantum effic-iency and preferentially horizontal emitting dipole orientation. Adv. Funct. Mater. 2020, 30, 1908839. [CrossRef]

32. Noda, H.; Nakanotani, H.; Adachi, C. Excited state engineering for efficient reverse intersystem crossing. Sci. Adv. 2018, 4, eaao6910. [CrossRef] [PubMed] 